\title{
Effects of Tail Docking Using a Rubber Ring With or Without Anesthetic on Behavior and Production of Lactating Cows
}

\author{
E. M. Tom, ${ }^{\star}$ I. J. H. Duncan, ${ }^{\star}$ T. M. Widowski, ${ }^{\star}$ K. G. Bateman,† and K. E. Leslie† \\ *Department of Animal and Poultry Science, \\ †Population Medicine, University of Guelph, \\ Guelph, Ontario, Canada, N1G 2W1
}

\section{ABSTRACT}

Production and behavioral measures were recorded to determine the level of stress and pain associated with tail docking adult dairy cows with a rubber ring. The possible advantages of using an epidural anesthetic were also examined. Sixty-four lactating, mixed-parity, Holstein cows were randomly assigned to one of four treatment groups. The treatments were rubber ring docking with epidural anesthetic (RRA), rubber ring docking without anesthetic (RR), control with epidural anesthetic (CA), and control without anesthetic (C). Behavior was examined on $\mathrm{d} 0,+1,+2$, and +6 . Milk production and feed intake were monitored. Cows exhibited subtle behavioral changes following application of rubber rings, as well as after epidural administration on $\mathrm{d} 0$ and tail amputation on $\mathrm{d}+6$. After treatment on $\mathrm{d} 0$, the RR, RRA, and CA groups displayed less tail shaking than the $\mathrm{C}$ group. The $\mathrm{RR}$ and RRA cows continued to exhibit less tail shaking on $d+1,+2$, and +6 . Also on $d$ 0 , the RR and RRA groups held their tails in the raised position less than the $\mathrm{C}$ and CA groups. After amputation on $d+6$, the RR and RRA groups spent longer with their tails pressed to their bodies than the $\mathrm{C}$ and $\mathrm{CA}$ groups. No significant differences in milk production or feed intake were found. Results suggest that taildocking adult dairy cattle with rubber rings causes, at most, mild discomfort and that there is no benefit in using an epidural anesthetic. However, long-term effects need to be investigated.

(Key Words: cow, tail docking, pain, behavior)

Abbreviation key: $\mathbf{C}=$ control, $\mathbf{C A}=$ control with epidural anesthetic, $\mathbf{R R}=$ rubber ring docking, $\mathbf{R R A}=$ rubber ring docking with epidural anesthetic.

\section{INTRODUCTION}

Tail docking of cattle is a common procedure on dairy farms in areas of the world including the United States,

Received December 16, 2001.

Accepted February 28, 2002.

${ }^{1}$ Corresponding author: I. J. H. Duncan; e-mail: iduncan@ uoguelph.ca.
Australia, New Zealand, and Canada. Tail docking usually involves applying a tight rubber ring around the tail at least a few centimeters below the level of the vulva (Petrie et al., 1995). The same kind of rubber ring routinely used to castrate bull calves is used in this procedure. The rubber ring causes a lack of oxygen in the tissues distal to the ring as a result of the diminished blood supply. The necrotic tail below the rubber ring is often amputated after $7 \mathrm{~d}$ or it will eventually fall off on its own.

This procedure is carried out principally for the gain of the dairy producer, with the objective of enhancing udder and milk hygiene and improving milker comfort during milking. Advocates of tail docking also claim it decreases the incidence of mastitis, a possible welfare benefit to the cow itself. Support for these claims is largely anecdotal, and most research on the possible benefits of tail docking dairy cattle has not proven any advantage (Matthews et al., 1995; Tucker et al., 2001). Furthermore, in addition to determining whether the putative benefits of tail docking actually do exist, it is crucial that any possible advantages be weighed against the drawbacks (including any potential acute pain) for the animal.

Few studies have examined the response of adult cows to tail docking with a rubber ring. In an early experiment, Wilson (1972) measured plasma cortisol concentrations from 15 docked cows and their intact twins at 6, 24, 48, 72, and $96 \mathrm{~h}$ after rubber ring application. Cortisol concentrations were significantly higher at the time of the first sample, $6 \mathrm{~h}$ after docking (although actual cortisol concentrations were not reported), and then returned to baseline levels by the next sample time, $24 \mathrm{~h}$ after docking. The author stated that no exaggerated signs of pain or discomfort were seen; however, the specific behaviors examined were not described (Wilson, 1972).

More recently, Eicher et al. (2000) examined 21 pregnant heifers, 1 mo before calving, to detect potential stress responses associated with the tail docking procedure. Rubber rings were applied on $\mathrm{d} 1$ and the necrotic tail was removed on $d 6$. Changes in cortisol concentration and behavior, as well as immunological measures 
were examined around the time of rubber ring application and removal of the tail. Differences in eating behavior and immunological measures were found. It was concluded that application of rubber rings appears only mildly stressful for the cow. Interestingly, the authors also reported that the actual amputation of the tail on d 6 caused discomfort, a possibility that had not been examined in earlier research (Eicher et al., 2000).

A small number of studies have been carried out on the effectiveness of local anesthetic in decreasing the possible physiological and behavioral response indicating pain associated with tail docking cattle. Petrie et al. (1995) found that the use of an epidural local anesthetic ( $3 \mathrm{ml}$ of lignocaine hydrochloride), given $10 \mathrm{~min}$ before application of the rubber ring, inhibited the behavioral response of 3- to 4-mo-old calves for $2.5 \mathrm{~h}$. Length of coverage of the anesthetic is thought to be approximately $2 \mathrm{~h}$, while the limited research on tail docking calves has determined that behavior indicating mild discomfort peaks within 1 to $1.5 \mathrm{~h}$ (Petrie et al., 1995). However, those animals given an epidural anesthetic displayed behavioral differences that began $2 \mathrm{~h}$ after docking, and such behavior was not observed in the other tail-docked calves at that time. The authors suggested that those changes in behavior may have been due to irritation caused by the local anesthetic wearing off, but could not confirm this hypothesis due to a lack of an anesthetic control group (Petrie et al., 1995).

In a later study, Petrie et al. (1996) found no detectable benefit of using the epidural anesthetic $(3 \mathrm{ml}$ of $2 \%$ lignocaine hydrochloride) based on the cortisol response of calves to docking with rubber rings or a docking iron. In fact, in some cases, the use of a local anesthetic seemed to have increased the cortisol responses to the rubber rings or docking iron, suggesting that the anesthetic may be more stressful in cattle than the actual application of the rubber ring and the ischemia that follows.

It is usually recommended that procedures such as castrating, dehorning, and tail docking be performed when the animal is young. Research examining the cortisol and behavioral responses of young calves to tail docking using a rubber ring determined that the procedure caused, at most, mild distress (Petrie et al., 1995, 1996; Tom et al., 2002). However, when producers make the decision to dock their dairy herds, they are likely to start by performing the procedure on the entire herd, including adult cows, and then routinely dock new animals as they are brought into the herd. In addition, some producers choose to routinely dock tails of heifers shortly before first calving. Overall, the research examining the welfare costs of tail docking of adult dairy cows is limited. The objective of this study was to measure the possible adverse effects, particularly in terms of acute pain, of docking tails of lactating dairy cows using rubber rings. The possible benefits of using an epidural anesthetic were also examined.

\section{MATERIALS AND METHODS}

\section{Animals and Housing}

Sixty-four lactating Holstein cows, from the Elora Dairy Research Centre, housed in tie stalls $(119 \times 190$ $\mathrm{cm})$ with straw bedding and milked twice daily $(0600$ and $1600 \mathrm{~h}$ ) were used in this study during May and June of 1999. Each day at 1400 h, the cows were let out into an outside yard with concrete surface for approximately $1 \mathrm{~h}$. Estrus was determined by behavioral signs displayed when the cows were in the exercise yard. The cows were fed a TMR twice daily (0630 and $1300 \mathrm{~h}$ ) consisting of haylage, corn silage, high moisture corn, protein supplement, and mineral premix. Water was available ad libitum from a nose-press water bowl in each stall. Cows due to be dried within the next 2 wk or cows that had calved within the previous $2 \mathrm{wk}$ were not included in the study. As a preventative measure, all animals were vaccinated against tetanus $(\mathrm{Co}-$ vexin 8, Schering-Plough Animal Health, Pointe Claire, PQ, Canada) 1 wk before each trial began. Two days (d -2) before treatment, all cows were clipped along the last few lumbar vertebrae and the sacrum to facilitate epidural administration.

\section{Experimental Design}

Experimental procedures were approved by the University of Guelph Animal Care Committee, complying with the requirements of the Canadian Council for Animal Care. The experiment was a $2 \times 2$ factorial in a randomized complete block design with tail docking and epidural anesthetic as the main factors. Cows were randomly allocated to each treatment group for both main effects $(n=32)$. The groups were balanced for milk production and parity but not stage of lactation. The study was divided into four blocks of time, approximately at 1 -wk intervals. Within each block, four different cows from each treatment group were allotted to a subblock based on milk production, resulting in 16 cows being observed per block. Cows remained in their original tie stalls, randomly located throughout the barn and, therefore, two cows from different treatments were occasionally housed beside each other. The treatment combinations ( $\mathrm{n}=16 \mathrm{cows} /$ treatment group) were docking with epidural anesthetic (RRA), docking without anesthetic (RR), control with epidural anesthetic (CA), and control without anesthetic (C).

On the morning of $d 0$, cows in the RRA and CA groups were given a caudal epidural anesthetic $(4 \mathrm{ml}$ 
Table 1. Definitions of postures observed using instantaneous scan sampling.

\begin{tabular}{ll}
\hline Posture observed & Definition \\
\hline Normal ventral lying & $\begin{array}{l}\text { The cow was lying on its sternum with all legs folded under the } \\
\text { body or one or both front legs extended with its head held up or } \\
\text { down (Molony et al., 1995). }\end{array}$ \\
The cow was lying on its sternum with full or partial extension \\
of one or both hind legs (Molony et al., 1995). \\
The cow was lying on its side with one shoulder and hindquarter \\
on the ground with two or more legs extended (Molony et al., \\
1995). \\
The cow was supported by four legs.
\end{tabular}

of lidocaine $\mathrm{HCl} 2 \%$ with epinephrine, MTC, Cambridge, ON, Canada) between first and second coccygeal vertebrae. A 10-min interval was allowed between the epidural injection and the application of the rubber ring to allow the anesthetic to take effect. Efficacy of the anesthetic was tested by lifting and moving the tail to confirm that it was limp and without muscle tone. Next, cows in the RRA and RR groups were restrained and their tails banded with round latex castrating rings (3 mm thick, with an inner diameter of $7 \mathrm{~mm}$, Ideal Instruments, Schiller Park, IL) $10 \mathrm{~cm}$ below the level of the vulva. Also at this time, cows in the $\mathrm{C}$ and $\mathrm{CA}$ groups were restrained and had their tails manipulated for the same amount of time as those in the RR group but without ring application. These procedures were carried out in random order based on where each cow resided in the row of tie stalls and were completed after approximately $15 \mathrm{~min}$ in total. On completion of these procedures, a cuff made of 3M Vet rap (3M Canada Inc., London, ON, Canada) and duct tape was applied to all the cows' tails, covering the rubber ring or, in the case of the $\mathrm{C}$ and CA cows, the corresponding area of the tail. The cuffs were examined and, if necessary, reapplied on the mornings of day $+1,+2$, and +6 before the observers entered the study area. All epidural administration, rubber ring application, and tail bandaging was done by the herd veterinarian to prevent observers of cow behavior from distinguishing among treatment groups, thus resulting in a blind study at least until day +6 . In the case of groups RR and RRA, the tail distal to the rubber ring was surgically amputated $1 \mathrm{~cm}$ distal to the rubber ring on day +6 to remove the dead tissue.

\section{Variables Measured}

Behavioral observations. The behavior of each cow was directly recorded in three observation periods each day. Each of two observers monitored eight cows in the order in which they resided in the row of tie stalls. The observers stood in the aisle behind the cows and moved down the aisle as each focal cow was observed. The cows were habituated to workers in this area because barn staff often walked in these aisles. Each observation period began by recording the postures (Table 1) and tail positions (Table 2) of all eight cows using instantaneous scan sampling. Next, the observer noted the respiration rate of the focal cow by counting the rising and falling of the chest over $30 \mathrm{~s}$. This was followed by a 90 -s period of focal-animal sampling to record the frequency of the cow's active behavior (Table 3 ). This process was then repeated with the next focal animal, starting again with a scan sampling of all eight cows. After each cow had been observed, the entire cycle was repeated two more times starting with the first focal animal. This resulted in a total of 24 instantaneous scan samples of postures and tail positions and $4.5 \mathrm{~min}$ of focal animal sampling per cow in each observation period (approximately $1 \mathrm{~h}$ in length). Standing and lying postures were analyzed as a percentage of scan samples and averaged across observation periods per day. Tail positions were analyzed as frequencies of cows displaying each position per day. Active behavior was analyzed as average frequency per observation period each day.

Observations were taken on $\mathrm{d} 0,+1,+2$, and +6 from 1030 to $1130 \mathrm{~h}, 1200$ to $1300 \mathrm{~h}$, and 1300 to $1400 \mathrm{~h}$. On d 0, rubber ring application and epidural administration took place between the first and second observation periods, with observations before treatment used as a baseline. On $d+6$, surgical removal of the tail occurred directly before the first observation period of the day.

Feed intake. TMR intakes were calculated using the amount of feed delivered minus the amount of refusal, and these were recorded twice daily from $d-3$ to +3 .

Milk production. Milk yields were recorded twice daily from $\mathrm{d}-6$ until +19 .

Cow health. Any cases of clinical mastitis were recorded based on a documented diagnosis by the herd veterinarian.

\section{Statistical Analyses}

All statistical tests were conducted using the SAS statistical software program (SAS, 1998). For active 
Table 2. Definitions of tail positions observed using instantaneous scan sampling.

\begin{tabular}{ll}
\hline Position observed & Definition \\
\hline Pressed & The tail was held against the anus and vulva. \\
Resting & The tail was in a relaxed position, not pressed up against the \\
& body or held out away from the body of the cow. \\
Raised & The tail was held away from the body, extending out more than \\
& $30^{\circ}$ from the body of the cow. \\
\hline
\end{tabular}

behavior and the duration of standing and lying, treatment comparisons were made for the observation period on $\mathrm{d} 0$ before treatment, the average of the two observation periods on $\mathrm{d} 0$ following the docking procedure, and the average of the three observation periods on $d$ 1,2 , and 6 . Because the observation periods were not evenly distributed with respect to the time of day and application of treatment, comparisons could not be made across days. Therefore, those behavior variables were analyzed within each observation day, as a $2 \times 2$ factorial in a randomized complete block design. Analyses of variance, using the GLM procedure, were used to examine the main effects of docking ( $1 \mathrm{df}$ ), anesthetic ( $1 \mathrm{df})$, and their interaction ( $1 \mathrm{df})$ tested against an error term ( $43 \mathrm{df}$ ) accounting for blocks over time (3 df) and subblock within block over time (12 df). When significant interactions were found between docking and anesthetic $(\alpha=0.05)$, Scheffe's procedure was used to compare means of treatment combinations. Before the analyses of variance, the UNIVARIATE procedure (SAS, 1998) was used to generate plots of residual versus predicted values. Data that displayed heterogeneity of variance on visual inspection of these plots were transformed using a square root transformation.

Because most cows displayed the resting tail position on most occasions, and the raised and pressed positions were rare occurrences, there were many zero values for those measures. Consequently, the data were summed for each day and expressed as the frequency of cows displaying those tail positions. Fisher's exact tests, of two-way frequency tables, using the FREQ procedure (SAS, 1998), were used to determine whether the frequency distributions of cows exhibiting various tail positions per day ("all vs. some" for the resting tail position and "none vs. some" for the raised and pressed tail positions) differed from random expectation between main effects. Frequency distributions for treatment combinations were also examined using Fisher's exact

Table 3. Definitions of active behavior patterns observed using focal animal sampling.

\begin{tabular}{|c|c|}
\hline Behavior observed & Definition \\
\hline Defecate/urinate & The cow urinated or defecated. \\
\hline Drinking & The cow was drinking from the automatic waterer. \\
\hline Easing quarters & $\begin{array}{l}\text { The cow moved a front or hind leg in a less forceful manner } \\
\text { than foot stamping/kicking or the whole body was shifted or } \\
\text { eased without moving from the place of rest (Molony et al., } \\
\text { 1995). }\end{array}$ \\
\hline Eating & The cow was eating the total mixed ration. \\
\hline Foot stamping/kicking & $\begin{array}{l}\text { The cow lifted either a front leg or hind leg and stamped it on } \\
\text { the ground while standing or kicked outwards while standing or } \\
\text { lying (Molony et al., 1995). }\end{array}$ \\
\hline Head shaking & $\begin{array}{l}\text { The cow moved her head in a series of rapid side to side or up } \\
\text { and down movements. }\end{array}$ \\
\hline Head turning/grooming & $\begin{array}{l}\text { The cow turned her head more than } 90^{\circ} \text { to a point on the body } \\
\text { past the shoulder, included grooming (Molony et al., 1995). }\end{array}$ \\
\hline Immobility & $\begin{array}{l}\text { The cow was standing without movement for a period greater } \\
\text { than } 10 \text { seconds (Graham et al., 1997). }\end{array}$ \\
\hline Neck extension & $\begin{array}{l}\text { The cow extended her neck with nose pointed outwards or } \\
\text { upwards. }\end{array}$ \\
\hline Posture changing & The cow stood up (partly or fully) or lay down. \\
\hline Ruminating & $\begin{array}{l}\text { The cow was chewing without consuming feed for more than } 5 \\
\mathrm{~s} \text { (standing or lying). }\end{array}$ \\
\hline Stretching & $\begin{array}{l}\text { The cow extended a foreleg or hind leg in a stretching motion. } \\
\text { Stretches associated with urination were not recorded (Molony } \\
\text { et al., 1995). }\end{array}$ \\
\hline Tail shaking & $\begin{array}{l}\text { The cow moved her tail from side to side. A continuous series } \\
\text { of tail movements was recorded as one action (Molony et al., } \\
\text { 1995). }\end{array}$ \\
\hline Vocalization & Any sounds from the mouth including grunting. \\
\hline
\end{tabular}


Table 4. Number of cows displaying various tail positions before and after treatment $(\mathrm{n}=31)(P<0.05$ indicates a significant difference between groups within each day).

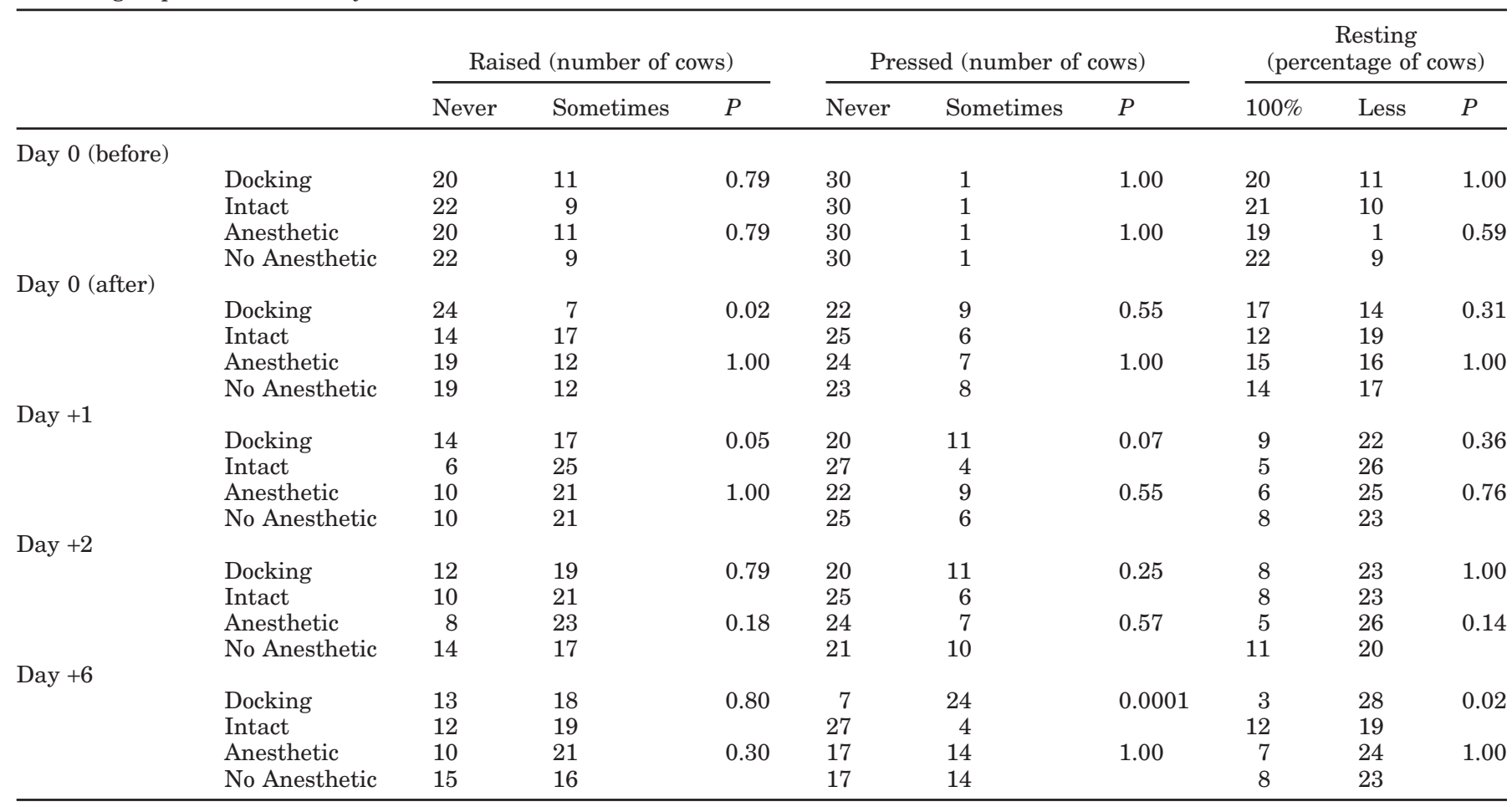

tests to determine any interactions between main effects. It is worth noting that a smaller number of observation periods were used to determine the frequency distributions both before and after treatment on $\mathrm{d} 0$; however, the number of observation periods was still balanced across treatments. This nonparametric procedure does not allow for a repeated measure design.

Because estrus can have a profound effect on both the behavior of cows (Pennington et al., 1985) and their milk production, a second series of analyses (after initial analyses which included data from all cows) was carried out excluding all data from animals (a total of eight cows, two from each treatment combination) that were in estrus, while behavior was being observed and milk production being recorded.

Because the docking procedure took place after the morning milking, but before the evening milking on $d$ 0 , daily milk production was defined as the sum of the evening milk production and the morning milk production values of the following day (i.e., milk production for $d+1$ is actually the sum of the milk produced in the evening on $d+1$ and the morning on $d+2$ ). Repeated measures analyses of variance, using the GLM procedure with the REPEATED statement (SAS, 1998), were used to examine the main effects of docking $(1 \mathrm{df})$, anesthetic ( $1 \mathrm{df})$, and their interaction ( $1 \mathrm{df})$ tested against an error term (43 df) accounting for blocks over time
(3 df) and subblock within block over time (12 df) on daily milk production and daily feed intake.

\section{RESULTS}

There were no differences between the initial analyses, including all cows, and the second analyses, excluding those cows displaying estrus, and the results from the initial analyses that include all cows are reported here. The rubber ring of one cow in the $R R$ group broke during the first week after application, and, therefore, that cow was removed from the study. As well, one cow from the CA group was diagnosed with mastitis before $\mathrm{d}+6$ (i.e., while behavior observations and feed intake were still being recorded) and was completely removed from the study.

\section{Behavior}

After docking on d 0, significantly more intact cows held their tails in the raised position than docked cows $(P<0.02)$. Those results are shown in Table 4 .

On $\mathrm{d}+6$, after amputation of the tail below the rubber ring, significantly more docked cows held their tails in the pressed position than did the intact cows $(P<$ 0.0001 ; Table 4). Also on $d+6$, fewer docked cows showed the resting tail position than did the intact cows 
$(P<0.02$; Table 4$)$. There were no other significant interactions between the main effects on the frequency of cows showing specific tail positions. There were no other significant effects of docking on tail position on any other days, nor were there any significant effects of anesthetic on tail position (Table 4).

There was a significant interaction $(P<0.03)$ between main effects (docking and anesthetic) on $d 0$ on the frequency of tail shaking. After time of docking on $\mathrm{d} 0$, the $\mathrm{C}$ group exhibited a significantly higher frequency of tail shaking than the $\mathrm{CA}(P<0.003), \mathrm{RR}(P<0.0005)$, or RRA $(P<0.0001)$ groups (mean $\pm \mathrm{SE}$ for $\mathrm{d} 0$ : $\mathrm{C}=2.3$ $\pm 0.5, \mathrm{CA}=0.7 \pm 0.2, \mathrm{RR}=0.5 \pm 0.1, \mathrm{RRA}=0.4 \pm 0.1$. There were no other significant interactions between the main effects. There was a significant effect of docking on the frequency of tail shaking on $d+1(P<0.0001)$, $+2(P<0.0001)$, and $+6(P<0.0001$; Table 5$)$ with the docked cows tail shaking less frequently than the intact cows. There was not a significant treatment effect on any other days for any other active behavior examined (Table 5).

There was no significant effect of docking on respiration rate on any of the days examined (mean $\pm \mathrm{SE}$ for d 0 docked $=47.7 \pm 2.1$ respirations $/ \mathrm{min}$, intact $=46.2$ \pm 2.4 respirations/min, $P>0.10$ ), nor was there an effect of anesthetic on respiration (mean $\pm \mathrm{SE}$ for $\mathrm{d} 0$ anesthetic $=48.0 \pm 2.2$ respirations $/ \mathrm{min}$, no anesthetic $=45.8$ \pm 2.3 respirations $/ \mathrm{min}, P>0.10$ ). There were no signifi- cant interactions between the main effects on respiration rate.

There were no other behavioral differences between the groups. The incidences of "drinking," "neck extension," "stretching," "posture changing," "foot stamping," "head turning," "defecate/urinate," "immobile," and "vocalisation" were very low ( $<10 \%$ of cows) and so those behaviors were excluded from statistical analysis.

The incidence of "lateral lying" and "abnormal ventral lying" were also very rare $(<10 \%$ of cows displayed these postures at any point in the study), so they were grouped with "normal ventral lying" and not analyzed separately. No significant differences in the time spent standing and lying were detected for any treatment groups (Table 6), and there were no interactions between anesthetic and docking.

\section{Feed Intake}

No significant effect of anesthetic or docking on feed intake was detected at any time during the study (Figure $1 \mathrm{a}$ and $\mathrm{b}$ ), and there were no interactions between anesthetic and docking $(P>0.10)$.

\section{Milk Production}

No significant effect of anesthetic or docking on milk production was detected at any time during the study

Table 5. Frequency of specific behavior during each observation period (mean \pm SEM) before and after treatment (tail docking with or without anesthetic). Within each day and behavioral category, different letters indicate a significant difference between groups $(P<0.05)$.

\begin{tabular}{lllllll}
\hline Behavior & Group & $\begin{array}{l}\text { Day 0 } \\
\text { (before) }\end{array}$ & $\begin{array}{l}\text { Day } 0 \\
\text { (after) }\end{array}$ & Day +1 & Day +2 & Day +6 \\
\hline Eating & Docking & $0.2 \pm 0.1$ & $0.3 \pm 0.0$ & $0.3 \pm 0.0$ & $0.3 \pm 0.0$ & $0.3 \pm 0.0$ \\
& Intact & $0.2 \pm 0.1$ & $0.3 \pm 0.0$ & $0.3 \pm 0.0$ & $0.3 \pm 0.0$ & $0.3 \pm 0.0$ \\
& Anesthetic & $0.2 \pm 0.1$ & $0.3 \pm 0.0$ & $0.3 \pm 0.0$ & $0.3 \pm 0.0$ & $0.3 \pm 0.0$ \\
& No anesthetic & $0.2 \pm 0.1$ & $0.4 \pm 0.0$ & $0.3 \pm 0.0$ & $0.3 \pm 0.0$ & $0.3 \pm 0.0$ \\
Ruminating & Docking & $0.3 \pm 0.1$ & $0.3 \pm 0.0$ & $0.3 \pm 0.0$ & $0.3 \pm 0.0$ & $0.3 \pm 0.0$ \\
& Intact & $0.4 \pm 0.1$ & $0.4 \pm 0.0$ & $0.3 \pm 0.0$ & $0.3 \pm 0.0$ & $0.3 \pm 0.0$ \\
& Anesthetic & $0.3 \pm 0.1$ & $0.4 \pm 0.0$ & $0.3 \pm 0.0$ & $0.3 \pm 0.0$ & $0.3 \pm 0.0$ \\
& No anesthetic & $0.4 \pm 0.1$ & $0.3 \pm 0.0$ & $0.3 \pm 0.0$ & $0.3 \pm 0.0$ & $0.3 \pm 0.0$ \\
Head turning & Docking & $0.4 \pm 0.1$ & $0.3 \pm 0.1$ & $0.3 \pm 0.1$ & $0.3 \pm 0.0$ & $0.2 \pm 0.1$ \\
& Intact & $0.4 \pm 0.1$ & $0.2 \pm 0.0$ & $0.3 \pm 0.0$ & $0.3 \pm 0.1$ & $0.2 \pm 0.0$ \\
& Anesthetic & $0.3 \pm 0.1$ & $0.3 \pm 0.0$ & $0.3 \pm 0.0$ & $0.3 \pm 0.1$ & $0.3 \pm 0.1$ \\
& No anesthetic & $0.4 \pm 0.1$ & $0.3 \pm 0.0$ & $0.3 \pm 0.1$ & $0.3 \pm 0.0$ & $0.1 \pm 0.0$ \\
Easing quarters & Docking & $0.8 \pm 0.2$ & $0.9 \pm 0.1$ & $0.8 \pm 0.2$ & $0.9 \pm 0.2$ & $0.8 \pm 0.1$ \\
& Intact & $0.7 \pm 0.2$ & $0.8 \pm 0.1$ & $0.7 \pm 0.1$ & $0.7 \pm 0.1$ & $0.6 \pm 0.1$ \\
& Anesthetic & $0.6 \pm 0.1$ & $0.8 \pm 0.1$ & $0.6 \pm 0.1$ & $0.5 \pm 0.1$ & $0.7 \pm 0.1$ \\
& No anesthetic & $0.8 \pm 0.2$ & $0.8 \pm 0.1$ & $0.9 \pm 0.2$ & $1.1 \pm 0.2$ & $0.8 \pm 0.1$ \\
Tail shaking & Docking & $1.4 \pm 0.3$ & $*$ & $0.8 \pm 0.2^{\mathrm{a}}$ & $0.8 \pm 0.2^{\mathrm{a}}$ & $0.4 \pm 0.2^{\mathrm{a}}$ \\
& Intact & $1.1 \pm 0.2$ & $*$ & $1.9 \pm 0.3^{\mathrm{b}}$ & $1.9 \pm 0.2^{\mathrm{b}}$ & $1.9 \pm 0.3^{\mathrm{b}}$ \\
& Anesthetic & $1.3 \pm 0.2$ & $*$ & $1.4 \pm 0.2$ & $1.3 \pm 0.2$ & $1.1 \pm 0.3$ \\
& No anesthetic & $1.2 \pm 0.3$ & $*$ & $1.3 \pm 0.2$ & $1.4 \pm 0.2$ & $1.2 \pm 0.3$ \\
\hline
\end{tabular}

*Interaction between main effects. 
Table 6. Percentage of time spent standing and lying during each observation period (mean \pm SEM) before and after treatment (tail docking with or without anesthetic). Comparisons within each day and behavioral category revealed no significant differences among groups.

\begin{tabular}{lllllll}
\hline Behavior & Group & $\begin{array}{l}\text { Day 0 } \\
\text { (before) }\end{array}$ & $\begin{array}{l}\text { Day 0 } \\
\text { (after) }\end{array}$ & Day +1 & Day +2 & Day +6 \\
\hline Standing & Docking & $47.3 \pm 6.8$ & $61.8 \pm 3.8$ & $59.5 \pm 3.2$ & $57.9 \pm 3.7$ & $61.0 \pm 3.9$ \\
& Intact & $42.4 \pm 6.5$ & $62.8 \pm 3.2$ & $62.3 \pm 2.3$ & $61.0 \pm 3.2$ & $58.5 \pm 2.8$ \\
& Anesthetic & $37.5 \pm 6.4$ & $63.3 \pm 3.7$ & $59.6 \pm 2.8$ & $54.6 \pm 3.4$ & $57.2 \pm 3.5$ \\
\multirow{4}{*}{ Lying } & No anesthetic & $52.3 \pm 6.7$ & $61.3 \pm 3.3$ & $62.2 \pm 2.7$ & $64.3 \pm 3.3$ & $62.3 \pm 3.2$ \\
& Docking & $52.7 \pm 6.8$ & $38.2 \pm 3.8$ & $40.5 \pm 3.2$ & $42.5 \pm 3.7$ & $39.0 \pm 3.9$ \\
& Intact & $57.6 \pm 6.5$ & $37.2 \pm 3.2$ & $37.7 \pm 2.3$ & $39.0 \pm 3.2$ & $41.5 \pm 2.8$ \\
& Anesthetic & $62.5 \pm 6.4$ & $36.7 \pm 3.7$ & $40.4 \pm 2.8$ & $45.4 \pm 3.4$ & $42.8 \pm 3.5$ \\
& No anesthetic & $47.7 \pm 6.7$ & $38.7 \pm 3.3$ & $37.8 \pm 2.7$ & $35.7 \pm 3.3$ & $37.7 \pm 3.0$ \\
\hline
\end{tabular}

A

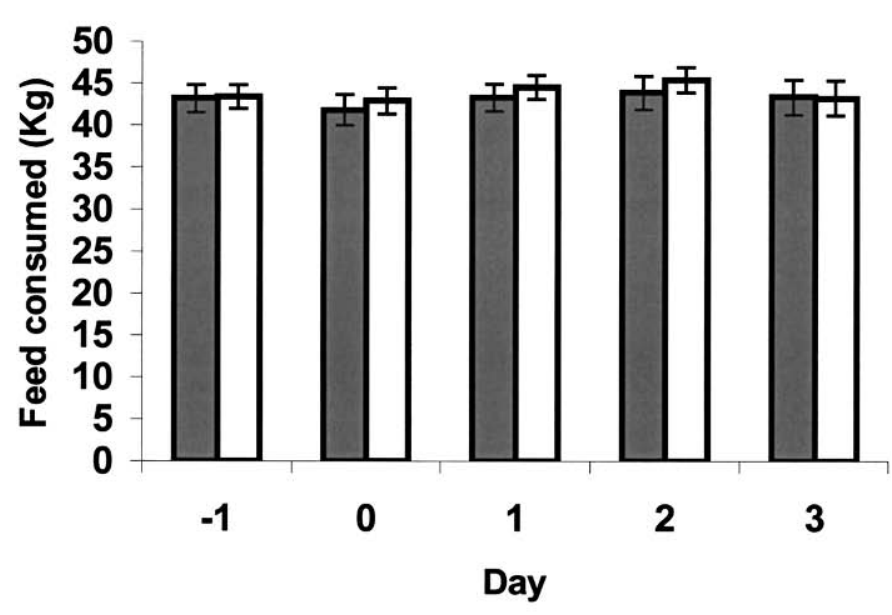

B

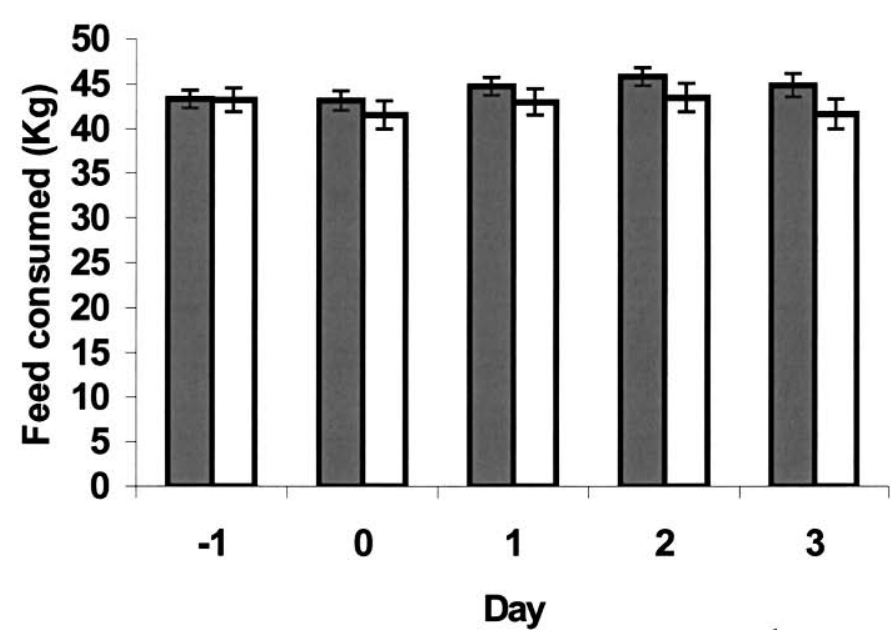

Figure 1. (a) Daily intake of TMR (mean \pm SEM) before and after treatment (docking or intact). (b) Daily intake of total mixed ration (mean \pm SEM) before and after treatment (anesthetic or no anesthetic).
(Figure 2a and $b$ ), and there were no interactions between anesthetic and docking $(P>0.10)$.

\section{DISCUSSION}

Overall, the cows studied in this experiment showed very few indications of pain or discomfort associated with rubber ring application at any time during the study. Accordingly, there was no benefit to using an epidural anesthetic. It is important to note that considering the number of statistical analyses used, it is possible that the few significant differences found may have been due to chance alone; however, this does not change the overall conclusions of the study.

Behavioral responses were limited to the tail region and involved decreased tail shaking (which was still evident up to $d+6$ ) and decreased time spent with the tail in the raised position on $d 0$. Interestingly, differences in tail position were also found after tail amputation on $d+6$. Specifically, tail-docked cows spent more time with their tails pressed against their bodies. However, no other behavioral signs of pain or discomfort were shown and no differences in milk production or feed intake were found.

On d 0, decreased tail shaking was seen not only for the RR and RRA groups but also the CA group. It seems likely that the epidural anesthetic interfered with the cows' ability to move their tails, resulting in a decreased frequency of tail shaking. This is supported by the fact that the frequency of tail shaking by the CA group returned to control levels by $d+1$. However, the $R R$ and RRA groups continued to have a lower frequency of tail shaking on $d+1,+2$, and +6 . Wilson (1972) also reported that by $24 \mathrm{~h}$ after ring application, docked cows were more restricted in their tail movements. The decreased tail shaking by the docked cows in the current study could be as a result of the numbness that probably occurs as the tail's blood supply is cut off below the rubber ring. Alternatively, tail shaking may be painful after rubber ring application, causing the cows to keep their tails motionless. Molony and Kent (1997) describe 

DDocking DIntact

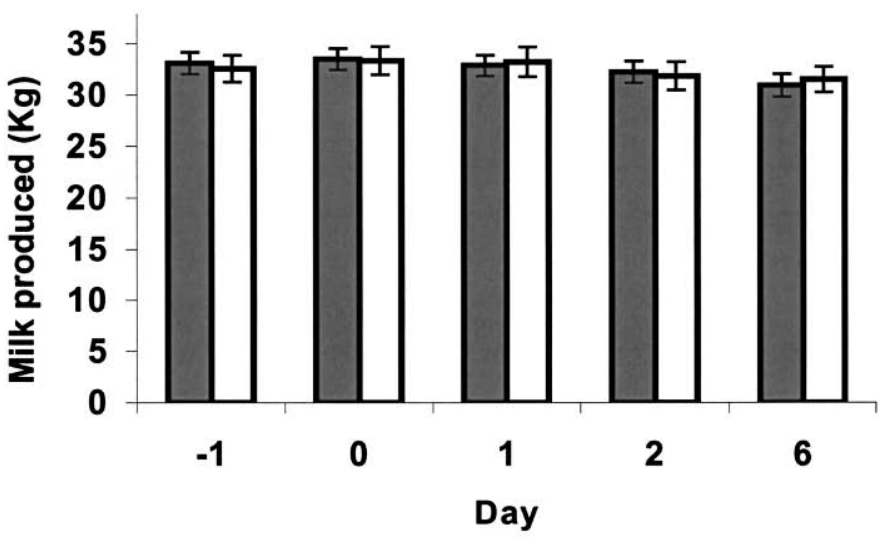

B

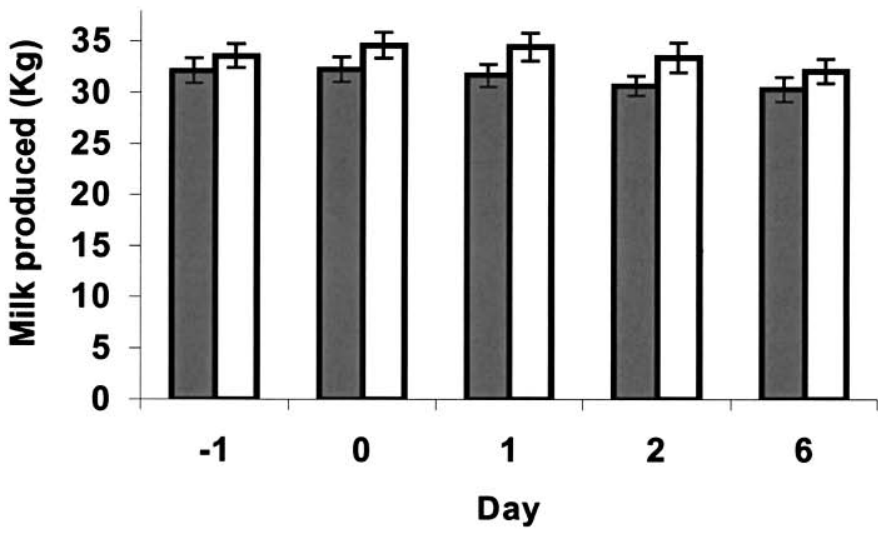

Figure 2. (a) Daily milk production (mean \pm SEM) before and after treatment (docking or intact). (b) Daily milk production (mean \pm SEM) before and after treatment (anesthetic or no anesthetic).

many different categories of pain responses, including those that minimize pain and assist healing, such as standing still, and this may be the response adopted here.

After application of the rubber ring on $\mathrm{d} 0$, the docked cows held their tails in the raised position less than the intact cows. Kiley-Worthington (1976) determined that cattle may raise their tails when they are in estrus, when a male is courting a female, during fighting and threatening, greeting and suckling. Because the cows in our study were housed in tie stalls and had little opportunity for interaction with other cows besides their direct neighbors, it is unlikely that the difference in tail raising was for any of these reasons. Regardless, we can conclude that docking with a rubber ring did inhibit the cows from raising their tails either by actually preventing the raising of the tail due to a lack of blood supply or again in order to minimize pain and assist healing.

After amputation of the tail on $d+6$, the docked cows spent a significantly greater proportion of time with their tail pressed against the body. Because there was virtually no response to the surgical amputation of the tail, with the exception of the occasional head turn that seemed due more to curiosity than discomfort, we suggest that those differences between the rubber ring and control groups may actually be due to a difference in the weight of the tail stump compared with the entire tail. As well, we cannot discount the possibility that the observers showed a bias when comparing the two very visually different groups. Nevertheless, we cannot rule out the possibility that this tail posture may be adopted due to the presence of some discomfort. In fact, it has been suggested in the past that cattle may press their tails against their bodies when in pain (KileyWorthington, 1976). Noonan et al. (1994) examined piglets after tail docking and also observed increased tail pressing or "tail jamming," which they suggested to indicate distress. Eicher et al. (2000) found decreased eating behavior and increased haptoglobin concentrations after tail amputation ( $6 \mathrm{~d}$ after rubber ring application), which they concluded indicated some discomfort associated with this procedure.

Although the observed changes in tail position and tail movement may be indicative of some discomfort following ring application and subsequent tail amputation, a lack of other responses leads us to believe the associated pain is minimal. Cattle in acute pain often show changes in posture, decreased feed intake, a sudden decrease in milk production, increased respiration rate, and an increased frequency of urination and defecation (Loeffler, 1986; Sanford et al., 1986; Whay, 1997). As well, vocalizations are considered a response to acute pain in many species (Sanford et al., 1986; Zimmermann, 1986; Molony and Kent, 1997). Furthermore, other common procedures performed on cattle, such as castration, dehorning and branding, elicit immediate responses including kicking, abnormal standing and lying postures, increased tail shaking, rearing, head shaking, and decreased rumination, which are likely indications of acute pain (Lay et al., 1992; Molony et al., 1995; Graf and Senn, 1999; Grøndahl-Nielson et al., 1999; Faulkner and Weary, 2000). None of this behavior was seen after ring application or tail amputation, suggesting that the discomfort experienced is mild at most. Accordingly, because there were no differences in the response of the rubber ring and rubber ring with anesthetic groups, we can conclude that the use of an epidural anesthetic is not beneficial. Not only does the anesthetic not decrease the response to tail docking, but its use can also add additional stress due to increased 
handling time and the risk of spinal abscess (Petrie et al., 1995).

\section{CONCLUSIONS}

The results from this study suggest that tail docking of lactating dairy cows causes only mild discomfort, and there is no advantage to using an epidural anesthetic. Amputation of the tail below the ring $6 \mathrm{~d}$ later may also cause some mild discomfort. Although the acute response to tail docking appears minimal, long-term effects must be considered before a final opinion is formed about the procedure. Tail-docked cattle have higher fly loads than intact cows and also show increased fly-directed behavior (Wilson, 1972; Ladewig and Matthews, 1992; Matthews et al., 1995), factors that may compromise their welfare. In addition, neuromas may form at the docking site, which may lead to chronic pain in the tail stump (French and Morgan, 1992; Gross and Carr, 1990). Neuroma formation has been reported in tail-docked lambs (French and Morgan, 1992), dogs (Gross and Carr, 1990), and most recently, calves (C. Lunam personal communication, 2001).

We have shown that the effects of tail docking on the dairy cow, in terms of acute pain and distress, are probably low. However, there are quite possibly other, longer-term adverse effects of the procedure that must be considered. Until benefits of tail docking have been proven and other potential welfare issues ruled out, routine tail docking should still be regarded as unnecessary and alternatives such as switch trimming should be considered.

\section{ACKNOWLEDGMENTS}

This research was supported by OMAFRA, NSERC, Agriculture and Agri-food Canada MII funds and the Dairy Farmers of Ontario. We wish to thank Dr. Rob Swackhammer, Meghan Brown, Steve Methot and the staff at the Elora Dairy Research Centre for their valuable assistance during this study.

\section{REFERENCES}

Eicher, S. D., J. L. Morrow-Tesch, J. L. Albright, J. W. Dailey, C. R. Young, and L. H. Stanker. 2000. Tail-docking influences on behavioral, immunological, and endocrine responses in dairy heifers. J. Dairy Sci. 83:1456-1462.

Faulkner, P. M., and D. M. Weary. 2000. Reducing pain after dehorning in dairy calves. J. Dairy Sci. 83:2037-2041.

French, N. P., and K. L. Morgan. 1992. Neuroma in docked lambs' tails. Res. Vet. Sci. 52:389-390.
Graf, B., and M. Senn. 1999. Behavioural and physiological responses of calves to dehorning by heat cauterization with or without local anaesthesia. Appl. Anim. Behav. Sci. 62:153-171.

Graham, M. J., J. E. Kent, and V. Molony. 1997. Effects of four analgesic treatments on the behavioural and cortisol responses of 3-week-old lambs to tail docking. Vet. J. 153:87-97.

Grøndahl-Nielson, C., H. B. Simonsen, J. D. Lund, and M. Hesselholt. 1999. Behavioural, endocrine and cardiac responses in young calves undergoing dehorning without and with use of sedation and analgesia. Vet. J. 158:14-20.

Gross, T. L., and S. H. Carr. 1990. Amputation neuroma of docked tails in dogs. Vet. Pathol. 27:61-62.

Kiley-Worthington, M. 1976. The tail movements of ungulates, canids and felids with particular reference to their causation and function as displays. Behaviour 56(1-2):69-115.

Ladewig, J., and L. R. Matthews. 1992. The importance of physiological measurements in farm animal stress research. Proc. N. Z. Soc. Anim. Prod. 52:77-79.

Lay, D. C., T. H. Friend, C. L. Bowers, K. K. Grissom, and O. C. Jenkins. 1992. A comparative physiological and behavioral study of freeze and hot-iron branding using dairy cows. J. Anim. Sci. 70:1121-1125.

Loeffler, K. 1986. Assessing pain by studying posture, activity and function. Pages 49-57 in I. J. H. Duncan and V. Molony, eds. Assessing Pain in Farm Animals. CEC Report, EUR 9742, Luxembourg.

Matthews, L. R., A. Phipps, G. A. Verkerk, D. Hart, J. N. Crockford, J. F. Carragher, and R. G. Harcourt. 1995. The effects of tail docking and trimming on milker comfort and dairy cattle health, welfare and production. Animal Behaviour and Welfare Research Centre, Hamilton, NZ.

Molony, V., and J. E. Kent. 1997. Assessment of acute pain in farm animals using behavioral and physiological measurements. J. Anim. Sci. 75:266-272.

Molony, V., J. E. Kent, and I. S. Robertson. 1995. Assessment of acute and chronic pain after different methods of castration of calves. Appl. Anim. Behav. Sci. 46:33-48.

Noonan, G. J., J. S. Rand, J. K. Blackshaw, and J. Priest. 1994. Behavioural observations of piglets undergoing tail docking, teeth clipping and ear notching. Appl. Anim. Behav. Sci. 39:203-213.

Pennington, J. A., J. L. Albright, and C. J. Callahan. 1985. Sexual activity of Holstein dairy heifers. Agri-practice 6:10-15.

Petrie, N. J., D. J. Mellor, K. J. Stafford, R. A. Bruce, and R. N. Ward. 1996. Cortisol responses of calves to two methods of tail docking used with or without local anaesthetic. N. Z. Vet. J. 44:4-8.

Petrie, N. J., K. J. Stafford, D. J. Mellor, R. A. Bruce, and R. N. Ward. 1995. The behaviour of calves tail docked with a rubber ring used with or without local anaesthetic. Proc. N. Z. Soc. Anim. Prod. 55:58-60.

Sanford, J., R. Ewbank, V. Molony, W. D. Tavernor, and O. Uvarov. 1986. Guidelines for the recognition and assessment of pain in animals. Vet. Rec. 118:334-338.

SAS. 1998. SAS user's guide: Statistics, Version 8 Edition. SAS Inst. Inc., Cary, NC.

Tom, E. M., J. Rushen, I. J. H. Duncan, and A. M. de Passillé. Behavioural, health and cortisol responses of young calves to tail docking using a rubber ring or docking iron. Can. J. Anim. Sci. 82:1-9.

Tucker, C. B., D. Fraser, and D. M. Weary. 2001. Tail docking dairy cattle: Effects on cow cleanliness and udder health. J. Dairy Sci. 84:84-87.

Whay, H. R. 1997. Pain in the lame cow. Irish Vet. J. 50:603-609.

Wilson, G. D. A. 1972. Docking cows' tails. Proc. Ruakura Farmer Conference, New Zealand: 158-165.

Zimmerman, M., 1986. Behavioural investigation of pain in animals. Pages 16-27 in Assessing Pain in Farm Animals. I. J. H. Duncan and V. Molony, eds. CEC Report, EUR 9742, Luxembourg. 